\title{
EDUCATION
}

\section{An Algorithm for Curriculum Decisions in Medical Laboratory Science Education}

\author{
SUSAN BECK, TARA C. MOON
}

\begin{abstract}
Advances in medical science occur at a dramatic rate, leading to new knowledge and technology that changes clinical laboratory practice. To prepare students for entry level practice and careers in the clinical laboratory profession, MLT and MLS educators need to continually review their curricula to decide what should be added or deleted. Decisions about deleting content are difficult but important in order to avoid curriculum saturation and to facilitate learning. This article presents a rationale for deleting some content and an algorithm that can guide decisions about what to teach and what not to teach.
\end{abstract}

ABBREVIATIONS: ASCLS - American Society for Clinical Laboratory Science, ASCP - American Society for Clinical Pathology, BOC - Board of Certification, CBC - Complete Blood Count, CLEC - Clinical Laboratory Educators' Conference, CLSI - Clinical Laboratory Standards Institute, FAB - French-AmericanBritish, MALDI-TOF - Matrix Assisted Laser Desorption/Ionization Time of Flight, MLS - Medical Laboratory Science, MLT - Medical Laboratory Technician, NAACLS - National Accrediting Agency for Clinical Laboratory Sciences, SSA - Sulfosalicylic Acid, WHO - World Health Organization

INDEX TERMS: Curriculum, Education, Professional, Faculty, Medical Laboratory Personnel

Clin Lab Sci 2017;30(2):105-111

Susan Beck, PhD, MLS(ASCP)CM, Division of Clinical Laboratory Science, Chapel Hill, NC

Tara C. Moon, PhD, MLS(ASCP $)^{C M}$, Division of Clinical Laboratory Science, Chapel Hill, NC

Address for Correspondence: Dr. Susan Beck, Division of Clinical Laboratory Science, 4114 Bondurant Hall,
CB \#7145, Chapel Hill, NC 27599-7145, 919-966-

3033,susan_beck@med.unc.edu

Curriculum Decisions in Medical Laboratory Science Education

Faculty members in medical laboratory educational programs are uniquely qualified to make decisions about what to include in a Medical Laboratory Science (MLS) or Medical Laboratory Technician (MLT) curriculum because of their professional education, credentials, and clinical experience. Most faculty members would agree that the decisions about what to include in the curriculum are not as difficult as the decisions about what not to teach. New information, new laboratory tests, and new protocols are constantly added to the laboratory profession. Adding new content to the curriculum is inevitable, but without simultaneously removing some of the older content, the MLS or MLT curriculum becomes unmanageable. This article presents an argument for deleting content from the MLS or MLT curriculum and an algorithm for making decisions about what to teach and what not to teach. The rationale for the algorithm, the algorithm, and the examples provided in this article are based on the experience and views of the authors. The authors welcome suggestions for improvement and additional examples.

The need to delete content from the curriculum.

Before discussing curriculum decisions in medical laboratory educational programs, it is helpful to first consider how students learn. No one theory of learning is adequate to explain the complexity of the human brain; however, the information processing theory or cognitive theory of learning provides a useful tool for discussing how we receive information and retain it for future use. A simplified version of the theory is shown in Figure 1.

The information processing theory postulates that we have three types of memory; sensory memory, working memory, and long term memory. Sensory memory pro- 


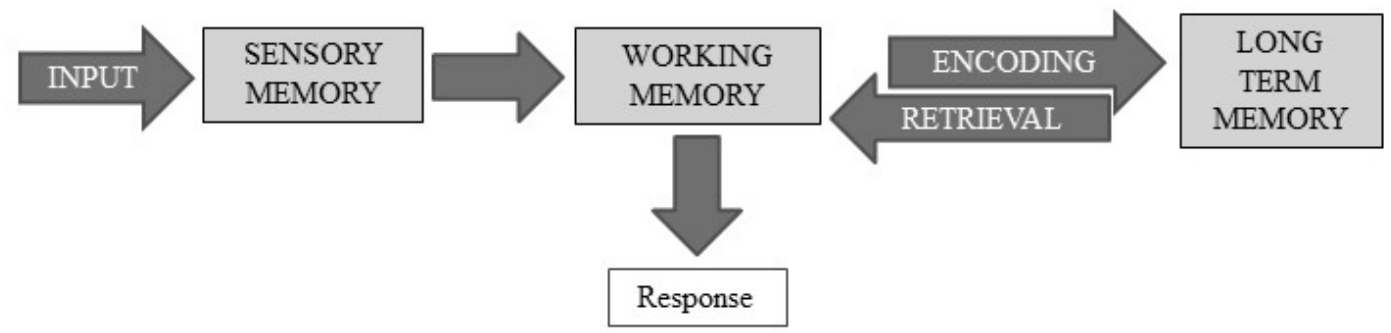

Figure 1. Information Processing Theory. ${ }^{1,2}$

cesses the incoming sensory information for very brief periods of time, usually 1 to 3 seconds. The amount of information held at any given time in sensory memory is limited to five to seven discrete elements such as a phone number. The main purpose of sensory memory is to screen incoming stimuli and process only those stimuli that are most relevant. For example, an MLS performing an $\mathrm{ABO}$ and $\mathrm{Rh}$ typing may be working in a busy, noisy laboratory but the MLS will focus on only those stimuli that are related to the accurate performance of the laboratory tests. After stimuli enter sensory memory, they are either forwarded to working memory or lost. In working memory, information is assigned meaning and linked to other information. Long-term memory is the permanent storehouse of information and is capable of retaining an unlimited amount of information. In long term memory, information must be organized and quickly accessible to be of practical use to learners. ${ }^{1,2}$

Two important components of the information processing theory of learning are encoding and retrieval. ${ }^{1,2}$ Encoding refers to a large number of strategies that move information from temporary storage in working memory into long-term memory. Examples include organization, inference, and elaboration strategies. Retrieval refers to processes that enable individuals to search for information in long term memory and move it to working memory for processing and response. If educators are simply putting information into a student's long term memory and not taking the time to help the student encode and retrieve the information, it may not be accessible to the student in the future. However, if educators lay a solid foundation and give students time to practice, use information to solve problems, and link information to other concepts, students will be exposed to less information but they will have the ability to use the information that they have. This has many implications for instruction including the use of practice, problem based learning, case studies, and other strategies that reinforce important concepts. In short, if educators want students to retain and use information, then less is more.

\section{Over-crowded curricula.}

Because adding content is so much easier than deleting content, most MLS and MLT programs suffer from curriculum saturation or over-crowded curricula. This problem is not unique to medical laboratory educational programs and has been discussed in nursing, pharmacy, and medicine., ${ }^{3,4}$ The Institute of Medicine report, "Health professions education: A bridge to quality", listed the "overly crowded curriculum" as one of the challenges facing those who would reform health professions education. ${ }^{5}$ It would be hard to find a more information dense profession than clinical laboratory science. The test directory at ARUP Laboratories, for example, lists over 3000 tests. ${ }^{6}$ Because it is not possible to include all the possible laboratory tests, microorganisms, blood groups and so on in an MLS or MLT curriculum, educators must draw the line at some point.

The second reason for overcrowded curricula in medical laboratory education is that MLS and MLT educators tend to be overly responsible. This quality is common in laboratory professionals who tend to go the extra mile to resolve problems and ensure that patients have accurate and timely laboratory results. As educators however, laboratory professionals may tend to take on more responsibility for student learning than they should. 


\section{EDUCATION}

Educators feel that it is their responsibility to make sure they have included every topic in their courses so their students will be well prepared. While educators may feel better because they have covered everything, they should consider whether or not including so much information in their courses means that the students actually learned it. Educators may simply be putting information into a student's long term memory that will never be retrieved.

Many MLS and MLT educators teach the way they were taught and that was often focused on the accumulation of knowledge. In this teacher-centered approach to education, the emphasis is on presenting content rather than the learning process. ${ }^{7}$ However, the health care system is not the same as it was when most MLS and MLT educators were students. The amount of knowledge that a laboratory professional can recall is not the key factor in providing excellent laboratory results and services. Rather, current practitioners need to have good communication skills, the ability to find the information they need to solve problems, and the ability to continue to learn. Some content in the curriculum may need to be deleted to make room for the learning experiences that facilitate the development of those skills.

Perhaps the biggest reason for over-crowded curricula in medical laboratory educational programs is the fear that omitting something might affect students' performance on certification examinations. Certification results are considered indicators of program success by the National Accrediting Agency for Clinical Laboratory Sciences (NAACLS) and by institutional administrators. The latest edition of the NAACLS Standards places a great deal of emphasis on program outcomes including certification pass rates and this has increased educators' anxieties about their students' performance.

The fear of omitting something that might be on the certification exam leads to a reluctance to delete anything from the curriculum. Comments like, "We don't do this anymore but they need to know it for the certification exam" are often heard. A good example of how an educational program dealt with this issue was reported by Doig and Hutchinson. ${ }^{8}$ They looked at their curriculum with the goal of removing content that was not current entry level practice. For example, they noted that the secretor test in blood banking was no longer being performed and therefore they decided that it would be deleted from the curriculum. They risked the possibility that their students might get a question wrong about the secretor test; however they felt that if their students were well prepared in the current areas of clinical practice, they would be able to pass the exam. Indeed, they found no difference in certification pass rates after they made that curriculum change.

Certification examination agencies should ensure that the exams cover current entry level practice. The American Society for Clinical Pathology Board of Certification (ASCP BOC) does this by conducting regular practice analyses to identify the knowledge and skills graduates need at career entry. ' Examination committees review the results of the practice analyses and regularly review the test item bank to ensure that the items reflect entry level practice. There is always a chance that a laboratory test method or content area would become outdated between practice analyses or between committee reviews because all of these processes take time. However, it is unlikely that one laboratory method or one fact will affect an individual's overall certification examination results. Educators must use their professional judgement to make decisions about the knowledge, skills, and attitudes that will best prepare students for entry level practice. If they address the most important information and concepts, their students should be successful on certification examinations. These decisions are not easy and must be done with input from a variety of sources. The algorithm presented in this article provides a structure for making those decisions.

\section{A systematic approach.}

An algorithm can serve as a support tool, or a way to organize a more systematic approach to the difficult questions about curricular content. This is a familiar process for laboratory professionals as algorithms are used in many areas of laboratory medicine to formulate decisions. In developing the algorithm for MLS/MLT curriculum decisions (Figure 2), several criteria were identified to help educators form a conclusion about a particular content area or test method.

Because a key criterion for the inclusion of a particular content area in the MLS/MLT curriculum is its use in current practice, this is where the algorithm begins. While it may be straightforward for many laboratory principles and methods, determining current practice for some topics is more challenging and may require consultation with one or more resources. Some resources 


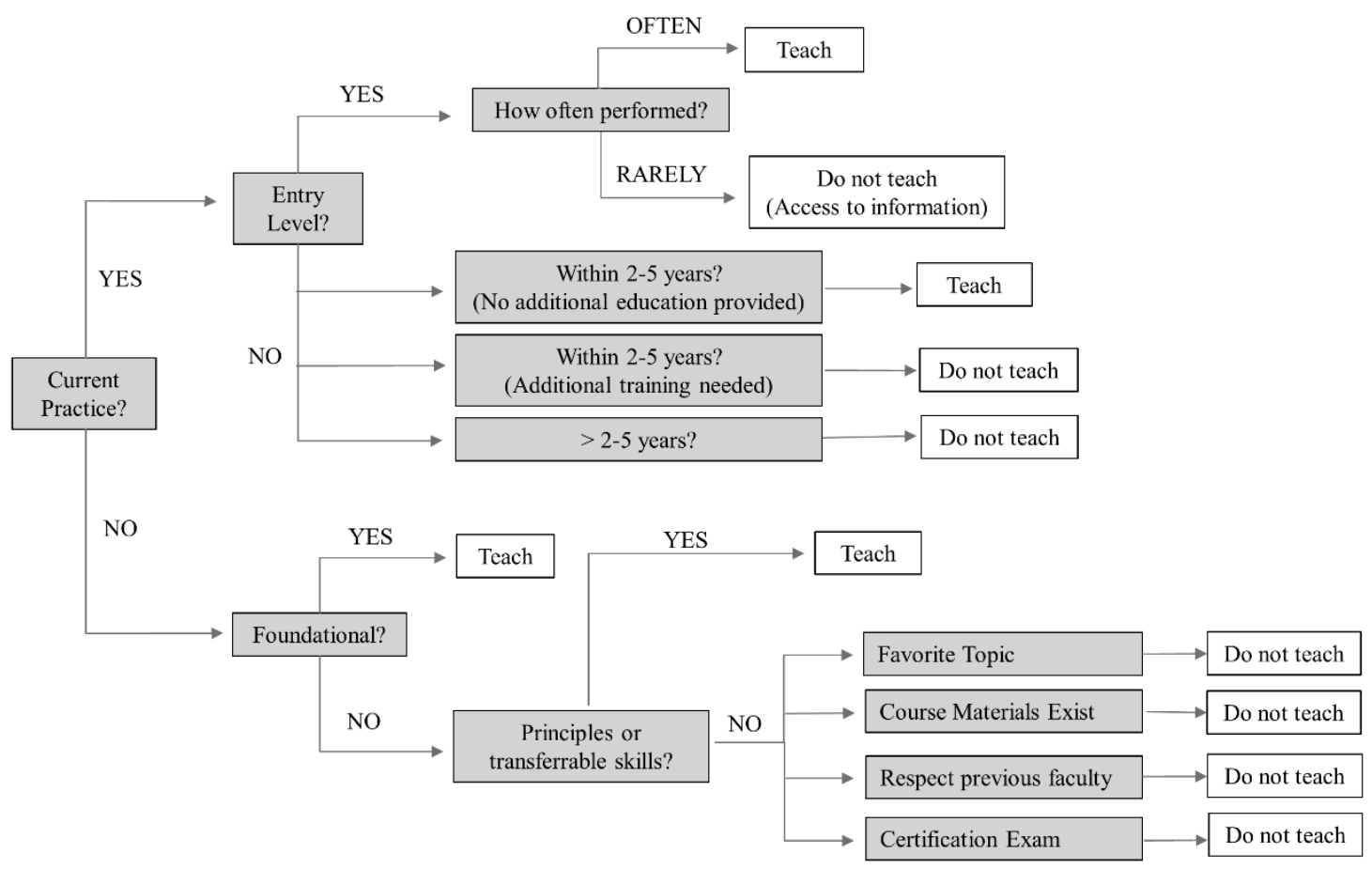

Figure 2. What Not to Teach Algorithm. A systematic approach to make decisions about what content to teach or not teach in the MLS/MLT curricula.

to help establish if a topic is current practice include the ASCP BOC content outlines (organized by technical level and by content area), and the American Society for Clinical Laboratory Science (ASCLS) Entry Level Curriculum..$^{10,11,12}$ Although a program's clinical sites can also be excellent resources for what is standard in the modern clinical laboratory, this should not be the only source relied upon. Programs should be preparing students for more than a single clinical site. For example, one site might be using gel technology exclusively in their transfusion service, but students need to know other current methods used for blood bank serology. Surveys of graduates and employers can also inform educators about current practice. Specific questions on surveys about the utility and necessity of the content in coursework and the curriculum can be especially useful to gauge current practice. Likewise, the program's advisory board, networking with other educators and colleagues using the educators' listserv, and professional meetings like the Clinical Laboratory Educators' Conference (CLEC) can help determine what is relevant in the modern laboratory. Other sources for workplace guidelines are the Clinical Laboratory Standards Institute (CLSI) documents, continuing education presentations at professional meetings, professional literature, and textbooks. Textbooks must be used with caution as they may not be as up-to-date as needed and they may include some outdated methods for completeness. Most importantly, educators should not underestimate their own expertise and should rely on their judgment as discipline experts along with these other resources to make curriculum decisions.

Once a topic is determined to be current practice, the top portion of the algorithm directs users to some other considerations. At this point, educators might contemplate if the topic is entry level and something that would be expected of a new graduate in their first year of practice. If so, then the frequency of its use should be taken into account. If it is something that is used or performed frequently, such as the common antibodies detected in immunohematology or common 


\section{EDUCATION}

microorganisms in microbiology, then it should be included in the curriculum. If it is rarely used or performed, then educators may need to decide not to teach it, and instead teach students how to access the information when needed. An example of this could be rare antibodies in immunohematology. Rather than have students memorize every possible antibody, educators can teach them how to recognize that a serologic pattern is not typical and how to search for more information.

If the topic is not entry level, it is important to identify at what point in practice it may become an expectation and if additional education is required. For example, if the topic is something that a graduate may be expected to do with 2-5 years of experience but additional education is not typically provided, then it should be taught within the curriculum. Examples of this at the MLS level could include laboratory administration, equipment purchasing, regulatory guidelines, education, research, or method validation. If the topic is something that a graduate might be expected to do within 2-5 years of practice, but additional training is typically required, then educators can consider not including this topic. For example, students may receive content regarding molecular pathology, but not necessarily become proficient in the technical skills to perform these assays. If the topic is something practitioners will need more than 5 years beyond graduation, then it can be excluded from the curriculum.

Even if a topic is not current practice, it still may have a valuable place in the MLS or MLT curriculum. The bottom portion of the algorithm suggests questions that educators ask to further explore topics that are not current practice. There are some occasions when it is necessary to teach a concept or procedure because it lays a foundation for the knowledge, skills or attitudes needed for entry level practice. For instance, in an MLS curriculum students may take a biochemistry course that provides the groundwork for future topics in clinical chemistry and for understanding molecular assays. Additionally, there might be other topics that demonstrate educational principles or transferable skills like creating a calibration curve manually or performing manual dilutions or titrations. These skills are required for understanding some more specialized methods or when troubleshooting some of the methodology within instrumentation.
There are other things to consider that may influence educators' decisions such as educator's preference for the topic. Often educators are energized by particular content areas or procedures; however, if it is only a favorite topic and does not meet any of the other criteria, then it is something that can be deleted. Similarly, educators often inherit course materials from previous faculty and may feel obligated to continue the legacy of a respected colleague. Educators should also consider if the decision to include the content is only due to a fear that it may appear on the certification exam. If there are topics that do not meet any of the other criteria presented here, then the educator should feel empowered to omit them.

\section{Examples}

In the dynamic clinical laboratory environment, there are many examples of topics that need to be evaluated for inclusion in the MLS or MLT curriculum. Examples of how one MLS program might use the algorithm to make these decisions are outlined in Table 1. The program might be considering whether manual chemistry methods should be included in a laboratory course. The performance of manual chemistry assays is certainly not current practice, but the technical skills required to carry out manual chemistry assays have a role in forming a foundation for many other curricular items throughout the MLS program and at entry level so the decision would be made to teach them.

\begin{tabular}{|c|c|c|}
\hline Topic/Skill & Question/Consideration & Answer \\
\hline Manual Chemistry & Is it current Practice? & No \\
\hline Assays & Does is lay a foundation? & Yes $\rightarrow$ Teach \\
\hline $\begin{array}{l}\text { Manual Complete } \\
\text { Blood Count }\end{array}$ & $\begin{array}{l}\text { Is it current practice? } \\
\text { Does it lay a foundation? } \\
\text { Does it demonstrate a } \\
\text { principle or transferrable } \\
\text { skill? }\end{array}$ & $\begin{array}{l}\text { No } \\
\text { No } \\
\text { Yes } \rightarrow \text { Teach }\end{array}$ \\
\hline $\begin{array}{l}\text { Microscopic } \\
\text { Evaluation of } \\
\text { Agglutination } \\
\text { (Immunohematology) }\end{array}$ & $\begin{array}{l}\text { Is it current practice? } \\
\text { Does it lay a foundation? } \\
\text { Does it demonstrate a } \\
\text { principle or transferrable } \\
\text { skill? }\end{array}$ & $\begin{array}{l}\text { No } \\
\text { No } \\
\text { No } \rightarrow \text { Do } \\
\text { not teach }\end{array}$ \\
\hline $\begin{array}{l}\text { Urine protein } \\
\text { sulfosalicylic acid } \\
\text { precipitation test } \\
\text { (SSA) }\end{array}$ & $\begin{array}{l}\text { Is it current practice? } \\
\text { Does it lay a foundation? } \\
\text { Does it demonstrate a } \\
\text { principle or transferrable } \\
\text { skill? }\end{array}$ & $\begin{array}{l}\text { No } \\
\text { No } \\
\text { No } \rightarrow \text { Do } \\
\text { not teach }\end{array}$ \\
\hline
\end{tabular}


Likewise, performing manual cell counts as part of a complete blood count (CBC) is not current practice as these are performed on automated analyzers in a modern clinical laboratory. These skills may not be foundational, but the ability to perform manual cell counts is a transferrable skill. While the routine CBC does not include manual cell counts, there are other areas of the laboratory (such as body fluids) where manual counts using a hemocytometer are essential. Again, the decision would be made to teach the skill.

A third example was a recent topic of discussion on the clinical laboratory science educators' listserv. Should programs teach students to read agglutination reactions microscopically for routine testing in transfusion medicine? Consulting practitioners at clinical sites, the AABB standards, and manufacturers' package inserts would lead the program faculty to the conclusion that this is not current practice. Following the algorithm, the next question is whether or not this represents a foundational principle or transferrable skill. The answer in this case is no and so the decision is "do not teach."

Another example is the urine protein sulfosalicylic acid precipitation test (SSA) which historically has been a part of MLS/MLT education. Although the SSA is an inexpensive and uncomplicated test to perform in the student laboratory, the results of the SSA are only crude estimates of urine protein concentration as the test lacks sensitivity and specificity and correlates poorly with quantitative urine protein determinations. ${ }^{13}$ When a confirmatory or quantitative test of urine protein is needed, current practice tends to require a 24-hour urine specimen or the urine protein-to-creatinine ratio, making the SSA an outdated method. ${ }^{14}$ SSA has also been removed from the entry level curriculum for urinalysis and for these reasons, educators should feel comfortable with a decision to not teach it. ${ }^{12}$

An area of current uncertainty might be the traditional biochemicals used for the identification of microorganisms due to the emergence of MALDI-TOF (Matrix Assisted Laser Desorption/Ionization Time of Flight) and its increasing use in the clinical microbiology laboratory. Also, educators may be considering whether or not to delete the French-American-British (FAB) classification system for hematologic diseases from their hematology courses and teach only the newer World Health Organization (WHO) classification system.
These are both examples of topic areas that are evolving and will need to be re-evaluated periodically.

\section{CONCLUSION}

MLT and MLS educators have an important role in continually monitoring the content of the curriculum, making curriculum decisions, and preparing students for an ever-changing field. They are uniquely qualified for this role because of their professional education, credentials, and clinical experience. This algorithm is presented as a tool for making those curriculum decisions and it will be improved as it is used in a variety of educational settings. The algorithm may also be useful for programs as they prepare for their NAACLS Self Study reports. Using the algorithm in discussions with faculty and advisory boards could lead to curriculum changes that could then be documented as examples or program improvement.

\section{ACKNOWLEDGEMENT}

The authors thank Dr. Kathy Doig for her careful review of the algorithm.

\section{REFERENCES}

1. Bell-Gredler M. Learning and Instruction. Theory into Practice. New York: MacMillan Publishing Company; 1986. p 151-190.

2. Huitt W. The information processing approach to cognition. Educational Psychology Interactive. Valdosta, GA: Valdosta State University; 2003. Available from http://www. edpsycinteractive.org/topics/cognition/infoproc.html. Accessed 2016 September 6.

3. Giddens J, Brady P. Rescuing Nursing Education from Content Saturation: The Case for a Concept-Based Curriculum. J Nursing Education 2007;46(2):65-9.

4. Achike F, Ogle C. Information Overload in the Teaching of Pharmacology. J Clin Pharmacol 2000;(40):177-83.

5. Institute of Medicine. Health professions education. A bridge to quality. Washington, D.C. National Academic Press;2003: p 38. Available from: http://www.nap.edu/read/10681/chapter/4\#38. Accessed 2016 September 6.

6. ARUP Laboratories: A National Reference Laboratory. Available from: http://www.aruplab.com/testing Accessed 2016 September 6.

7. Candela L, Dalley K, Benzel-Lindley J. A Case for LearningCentered Curricula. J Nursing Education 2006;(45)2:59-66.

8. Doig K, Hutchinson C. Risk Taking: Deciding what not to teach. Clin Lab Sci 1992;5(2):79-80.

9. Tanabe P. Understanding ASCP BOC Certification Examinations. E-links for Program directors. January/February 2016. The ASCP Board of Certification. Chicago, IL. Available from: https://s3.amazonaws.com/ascpcdn/static/BOC/elinks/ eLinks_2016_Jaunuary-February.html Accessed 2016 September 6.

10. American Society for Clinical Pathology Board of Certification. Medical Laboratory Scientist, MLS(ASCP), International 
Medical Laboratory Scientist, MLS(ASCP ${ }^{\mathrm{i}}$ Examination Content Guideline and Outline. Available from: https://www.ascp.org/content/docs/pdf/boc-pdfs/guidelines/ examinationcontentguidelinemls.pdf?sfvrsn=6 Accessed 2016 September 1.

11. American Society for Clinical Pathology Board of Certification. Medical Laboratory Technician, MLT(ASCP), International Medical Laboratory Technician, MLT(ASCPi) Examination Content Guideline and Outline. Available from: https://www.ascp.org/content/docs/default-source/pdf/bocpdfs/guidelines/examinationcontentguidelinemlt.pdf?sfvrsn $=4$ Accessed 2016 September 1.
12. American Society for Clinical Laboratory Science. Entry Level Curriculum for Medical Laboratory Scientist (MLS) and Medical Laboratory Technician (MLT). McLean, Virginia. 2016

13. Larson TS. Evaluation of proteinuria. Mayo Clin Proc 1994;69:1154-8.

14. Hanzlicek AS, Roof CJ, Sanderson MW, Grauer GF. Comparison of urine dipstick, sulfosalicylic acid, urine proteinto-creatinine ratio and a feline-specific immunoassay for detection of albuminuria in cats with chronic kidney disease. J Feline Med Surg, 2012:14(12):882-8.

\section{CLEC 2018 CALL FOR ABSTRACTS}

The deadline for abstracts for poster presentations or technology demonstrations at the 2018 ASCLS Clinical Laboratory Educators' Conference (CLEC) is October 2, 2017.

Submission instructions and the proposal form may be found at www.ascls.org/CLEC. The completed proposal form and abstract must be submitted electronically by the deadline.

The 2018 CLEC will be held February 22-24th in Houston, TX. Additional meeting information will be available at www.ascls.org/CLEC. 